\title{
Comparative Research on Education Facilities Change in the Sparsely Populated Rural of China and Japan*
}

\author{
Zang Zhiyong \\ Ningxia University, Yinchuan, Ningxia, China
}

\begin{abstract}
The population migration is a major feature of the development of human and social change. It relates to political, economic and cultural, as well as concerning the city modernization, industrialization, and many other factors. From 60's of the twentieth Century, the Japanese migrated from rural to urban and the rural population suddenly decreased. As a result, the rural population distribution gradually spared and the number of children decreased. So some rural schools be closed. It lead to the unsustainable to development of rural economy. At present, the same phenomenon appears in the Chinese rural. In order to solve the questions about the idle educational facilities in China rural, this project analyses some theory about sociology, pedagogy and econometric, citing the empirical analysis, referring the experience of Japan. It can provide reference for the the relevant government departments.
\end{abstract}

Keywords - The rural population distribution spared, Educational facilities, Facilities idle, Change the function

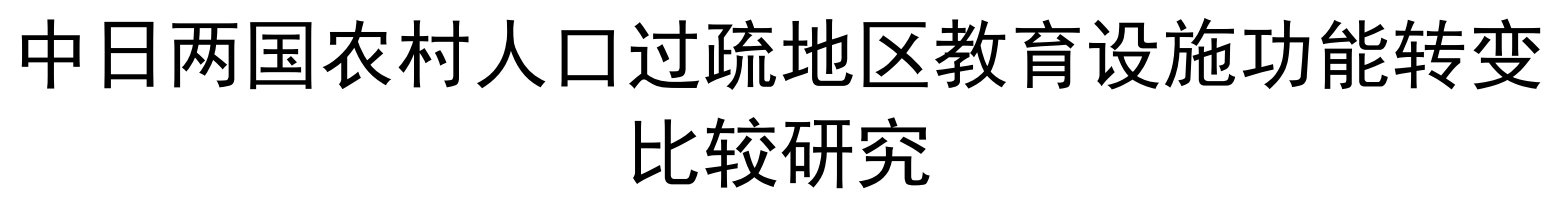

\author{
藏志勇 \\ 宁夏大学，银川，宁夏，中国
}

摘 要 人口迁移是人类发展和社会变迁的主要特征，它与政治、经济和文化，以及城市化和工业化等诸多因素有关。日本从 20 世纪 60 年代开始, 人口由农村向城镇迁移, 导致农村人口骤然减少, 出现农村地区的人口过疏和少子现象, 致使部分农村学校关闭, 出现中山间地区农村学校教育的空洞化, 严重影响了农村地区经济的可持续发展。目前, 中国农村, 特别是宁夏农村已出现了同迹现 象。本研究运用社会学、教育学和计量经济学的理念与实证分析法, 借鉴日本经验, 寻求我国农村地区因人口过疏引起的教育设施闲 置的解决模式或途径, 为我国振兴农村地区教育事业、构建和谐社会和政府相关部门制定决策提供参考依据。

关键词 农村人口过疏, 教育设施, 资源闲置, 功能转变

\section{1. 国内外研究综述}

\section{1 人口 “过疏” 概念的由来}

1966 年 3 月, 日本经济审议会在报告中最早提出了人 口 “过疏” 概念; 之后, 很多学者提出了 “过疏” 的观点, 认为过疏的核心是因人口向城市激烈的移动, 导致农村人 口减少而引发种种问题。代表人物: 伊藤善市 (1967)、安 达生恒（1967）、内藤正中（1968）、今井幸彦（1968）等。

\section{2 国内外专家学者的论述}

伊藤善市经过研究发现, 日本过疏问题研究领域形成
了 “现状维持论”、“积极开发论”、“据点形成论”、“集团 移动论”、“自由放任论”五大流派。现状维持论：主张不 直接触及过疏地域的经济构造和生活基础, 而是通过生活 保护及其他社会保障制度, 为地域居民提供最低限度的生 活保障措施, 这虽然比较符合居民的保守心理, 但不属于 解决问题的积极对策; 积极开发论: 主要包括离岛振兴法 和山村振兴法等, 但这种积极开发论要想变为现实, 必须 具备经济上的可行性和居民定居这两个条件; 据点形成论: 主张在过疏地域或其附近形成据点, 在那里建立完善的教 育、医疗、行政、福利设施等城市功能的同时, 整顿过疏 地区与该据点之间的交通、通信体系; 集团转移论: 是指

*本课题研究由 2010 年度宁夏大学社会科学重点项目资助, 课题编号: NDSK10-9。 
将过疏地域的居民作为一个自然村的整体, 直接转移到据 点地区; 自由放任论: 主张不采取以上诸项措施, 而任其 自然发展, 政府只提供信息情报供地区居民自由选择。

近年来中国学术界非常关注农村过疏化问题。程连生、 冯文勇 (2001) 认为: “居住在农村的住户, 在空间欲望驱 使下逐渐向周边新扩带迁, 导致原聚落成新度下降、非居 住房屋增加、废墟面积扩大、人口密度锐减, 并与新扩带 形成强烈反差的一种聚落形态。由原来成新度相对均质的 聚落, 发展为新旧二元结构的空心化聚落的过程”。何芳、 周璐（2010）认为: “所谓村庄空心化, 就是农村人口、资 源从农村内部区位资源禀赋不足地区向外围条件优越地区 和城镇转移, 造成村庄聚落人口流失、房屋闲置的结果”。

\section{2. 日本农村人口过疏地域特征及形成原因}

\section{1 地域特征}

在理解 “过疏” 一词时, 人们往往将其与人口问题相 联系, 认为其核心内容表现为区域内人口和户数锐减。但 由于离乡者大多为年轻人而使得这些过疏地区较早地进入 “老龄社会”, 地域活力严重不足, 生产规模缩小, 农村财 政能力、教育、医疗服务低下, 消防活动难以为继, 一些 传统的冠婚葬祭仪式也面临前所未有的困难。因此, 日本 学界将人口过疏地区的特征概括为: 分布面广; 人类生存 的自然条件和经济条件差; 地方政府财源少。地区人口普 遍高龄化, 是日本在工业化、产业化特定的社会变迁背景 下产生的一种社会现象。

\section{2 形成原因}

1955 年以后, 日本经济步入高速增长期, 以农村 (含 山村、渔村）人口为主体的地方人口迅速被城市、特别是 大城市所吸收。据统计, 在 1960 1979 年期间, 日本农业 人口从 3441 万人减为 2196 万人, 占总人口的比重从 $36.8 \%$ 下降到 19.1\%。

伴随着日本经济的迅速崛起, 日本的现代化和城市化 进程也大大加快。同时, 随之而来的是农村人口过疏现象。 过疏现象是日本经济高速发展过程中地区间社会经济发展 不平衡的一种表现, 这一现象突出地反映在人口分布上。 从日本农村过疏化现象产生的原因来看, 主要有以下几个 方面: 一是战后日本发展重心向城市倾斜; 二是工业现代 化的发展和产业结构升级; 三是农村小块土地所有制; 四 是农民价值倾向的变化。

\section{3. 日本对农村过疏地区以及闲置校舍制定的政策}

3.1 特殊政策
在过疏对策的演进过程中，日本在 1960 年代的经济高 速发展时期, 通过行政手段促进了过疏对策的实施。相继 制定和颁布的《过疏地域对策紧急措置法》(1970 年)、《过 疏地域振兴特别措置法》(1980 年) 及《过疏地域活性化特 别措置法》(1990 年) 等法规, 构成了日本过疏对策演进的 三个阶段，形成了复杂多元的 “过疏对策” 体系，使日本 地域间发展不平衡的问题有所改善，直接推动了地域协调 发展。在一定程度上保障和促进了日本农村经济的可持续 发展, 具体体现在农村工业和城市化的大力发展, 基本上 实现了农村工业化和现代化, 极大地加快了城市化和城乡 一体化进程。

\section{2 为教育设施制定的财政制度}

文部省在明确学校设施改革方向的同时, 也积极采取 政策支持, 进一步深化了学校设施改革。首先, 在财政方 面, 通过实施财政补助制度, 积极支持学校设施改革。按 照日本相关的法律规定, 公立学校设施的建设费应由学校 所在地的各级地方政府负担, 通过财政补助制度, 可以反 映出文部省对学校设施改革的支持力度。其次, 除了实施 财政补助制度外，文部省于 1991 年度开始实施了 “关于制 定学校设施建设指针的调查”，并制定了《学校设施建设指 针》, 为地方各级主管部门在学校设施新建和改扩建时, 起 到了方向性的指导作用, 这一系列举措, 收到了实效, 极 大地促进了日本学校设施的改革。

\section{3 立法规范使用闲置校舍}

随着出生率的下降, 日本 “少子化” 问题日益凸显, 过去投入大量经费修建的优质校舍, 因为学龄人口的减少 而闲置废弃。日本政府为了解决这一问题, 出台了《老人 福祉法》、《儿童福祉法》等法律, 对闲置教室、校舍的利 用做出了明确规定, 由地方公共团体承担设施配备建设及 所需资金, 建成儿童学习和生活的空间、教师进行上课准 备的空间、管理空间、学校向社会开放的空间等。如果一 所学校有较多的闲置教室, 可考虑将学校撤销, 积极地将 校舍改造成社会教育设施。为了促进农村和城市交流, 将 校舍改造成农业体验学习的旅居型活动设施, 日本农林水 产省、环境省、国土交通厅等多个部门进行合作, 为利用 闲置校舍提供了相关支持项目。

\section{4. 日本学校设施的改革与方针措施}

4.1 两次教育改革

一是向社会开放办学。为了适应今后社会发展的需要, 中央教育审议会于 1971 年发表了《关于今后学校教育综合 改革的基本方针》的教育改革方案, 该方案主张今后要 “开 
展适合个人能力与特点的教育”, “开发和正确利用适合个 人能力与特点的方法”, 创造 “根据能力进行区别指导的必 要条件”, 提倡 “学校向社会开放”, 提出了创造必要条件、 改善教学方法和开放学校等主张, 促进了学校设施的改革。

二是教育方法的多样化。日本政府为了进一步深化教 育改革, 成立了隶属总理大臣的临时教育审议会（该临时 教育审议会于 $1985 \sim 1989$ 年先后四次提出了教育改革方 案), 要点是 “重视个性的原则”、“向终身学习体系过度” 和 “适应新变化” 三个方面, 并对学校设施的改革进一步 提出了具体的要求, 积极从人性化的观点谋求教育条件的 改善, 在对包括室外环境在内的教育环境建设的同时, 进 一步充实这一环境, 使之能够有利于学生的个性发展、教 育内容的灵活性以及配合信息化实施教育方法的多样化, 进一步推动了学校设施的改革步伐, 为学校设施的改革指 明了具体的方向。

\section{2 学校设施改革的方针措施}

自 1970 年以来, 文部省多次组织各方面专家和学者召 开座谈会, 听取了社会各方面的意见和建议, 于 1985 年成 立了由专家组成的 “关于适合教育方法多样化等的学校设 施发展方向调查研究会”, 对全国学校设施状况进行了为期 两年的调查, 于 1988 年发表了研究报告。

该报告提出了今后学校设施改革的指导思想, 其主要 内容可以归纳为三个方面: 一是学校设施要促使教育方法 等的多样化。改革后的新型学校设施要有利于学生的个性 发展, 有利于多种学习指导方法、学习形态和教学模式的 展开; 二是要丰富教育环境。学校设施不仅仅是学习的场 所, 同时也是包括生活在内的教育环境, 因此, 建设一个 能够激发学习欲望和促进自主学习的学校设施至关重要。 三是增加学校设施的开放功能。教育改革目的之一是要 “向 终身教育过渡”, 这就要求全社会应该积极为终身教育提供 机会和创造条件。学校设施作为最贴近居民的学习设施, 积极倡导学校设施要向社会开放将会促进终身教育的发 展。

\section{5. 日本全国的废弃教育设施状况}

日本农村人口过疏地区发生废校的主要原因有三个: 一是因为过疏化引起儿童和学生减少; 二是住宅向郊外迁 移引起城市儿童和学生减少; 三是老龄化和少子化促使儿 童及学生减少。其中, 主要原因是儿童和学生的减少。因 过疏导致废校的比例占 $60 \%$ 。

据日本文部科学省「废校设施等活用状況实态调查」 的统计, 2011 年公立学校 (小学校、中学校、高等学校和 特別支援学校) 的废弃学校数字为 474 校。从 1992 年到 2011 年的 20 年间, 平均每年约有 $400 \sim 500$ 所左右的公立学校
被废弃, 总数达 6834 所学校。

从 2002 年到 2011 年废弃的 4222 所学校建筑物中, 有 2963 所、占 $70.2 \%$ 的学校资源被重新配置, 主要是由社会 体育、社会教育、体验交流、文化、老人福祉、保育院等 福祉以及民间企业或办公场所利用, 其它还有住宿、特产 专卖店和加工厂等。如将废校设施转作为保育院、高龄人 员福利设施、体验交流设施和创业孵化设施等被利用时, 国家的相关部门会给与一定的补助。

\section{6. 案例分析}

本课题组成员通过对日本全国闲置教育设施的统计分 析, 探讨了日本学校设施改革的发展动向, 于 2010 年 9 月 实地考察、调研了农村人口过疏地区小学校设施功能转变 事例, 考察了利用废弃的教育设施而建立的低碳型融雪低 温食品储藏实验室, 收集了大量的相关数据, 从中获取了 许多有益的资料。如: 始建于 1880 年的日本岛根县山区农 村的饭南町小田小学, 进人 1980 年代以后, 随着学校周围 人口大量迁移、人口老龄化等原因, 于 2005 年 3 月停学, 作为促进城市及当地居民交流的基地设施, 在 2009 年进行 了改建。将校舍的 1 楼作为当地的办公设施, 2 楼改建成 “故 乡回想馆”, 展示了日本从 1940 年代开始的生活、教育文 化和历史等相关的用具、实物。另外, 将纪录片刻录成光 盘, 以 “回想疗法” 传达 “治疗” 和 “平静” 的意欲, 促 进农村与城市居民的交流, 还建有 “农林业教室”、“生活 游戏教室”、“学习场景” 等, 反映了在社会急速变化的背 景下, 农村的生活方式和农村学校发生的巨变。

\section{7. 我国目前农村人口过疏地区教育面临的主要问题}

我国在改革开放以后, 随着城市化和工业化的迅猛发 展, 城市劳动力需求日益增多, 农村剩余劳动力过剩, 出 现了由农村涌向城市的 “民工潮”, 进而产生进城务工人员 随迁子女逐年增加、农村人口出生率持续降低、农村学龄 人口不断下降现象, 引起各地进行了对农村义务教育学校 的布局调整和撤并。据有关资料显示，从 2000 年到 2010 年十年间, 我国农村小学减少 22.94 万所、初中减少 1.06 万所; 小学生减少了 3153.49 万人、初中生减少了 1644 万 人; 教学点减少 11.1 万个; 农村平均每天消失 63 所小学、 30 个教学点、 3 所初中, 几乎每过 1 小时, 消失 4 所农村 学校。

为了解决农村的城镇化、工业化和学龄人口数量不断 下降等问题, 国家做出了对学校布局实施调整政策。比如, 2001 年颁布的《国务院关于基础教育改革与发展的决定》 中指出, 要因地制宜调整农村义务教育学校布局, 调整后 的校舍等资产要保证用于发展教育事业。2006 年, 教育部 发布的《关于实事求是地做好农村中小学布局调整工作的 
通知》中规定, 对于确需调整的学校, 调整后的教育资源 应主要用于举办学前教育、成人教育等机构; 确实闲置的 校园校舍, 应由县级教育行政部门统一处置, 处置所得应 用于当地发展义务教育。2012 年, 出台了《国务院办公厅 关于规范农村义务教育学校布局调整的意见》(国办发 [2012]48 号) 文件。该文件制定了应进一步加强和规范农 村教育设施管理等措施。

\section{8. 结论及建议}

综上所述, 日本工业化和现代化的发展是以牺牲农业 为代价的, 农业成为日本经济发展体系中的一个薄弱环节。 由于大量人口外出, 特别是年轻人外流, 导致农村尤其是 山村因失去年轻人而丧失活力。因此, 在人口过疏地域提 早进入 “老龄社会” 的条件下, 如何制定 “老龄对策”, 寻 找振兴过疏地域经济社会的主体力量, 就成为决定国家兴 衰的现实问题。

为了促进我国农村人口过疏地区教育设施功能转变, 应重点抓好以下几个方面的工作:

\section{1 加强政府管理职能}

明确农村中小学闲置校园校舍处置利用的原则、程序、 标准和税费减免等有关优惠政策, 规范处置行为, 建立长 效机制, 以严谨、科学、负责的态度来对待农村教育闲置 资源, 根据闲置校舍的利用价值、产权归属等情况, 对国 有资产、集体资产以及混合型资产分类指导, 进行集约化、 多功能改造与处置, 使农村闲置校园校舍在新农村建设和 农村乡土文化的保存与创新中焕发盖然生机。

\section{2 做好资产管理整顿}

由专门机构对闲置校舍逐校进行摸底排查, 登记造册, 全面掌握闲置学校的状况, 落实使用管理职责, 防止校舍 失管失修、闲置荒废。根据闲置校园校舍的利用价值、产 权归属等实际情况, 寻求最合理的利用方式。一是对没有 纠纷的闲置校产, 要优先在教育系统内划转使用, 比如优 先用于发展学前教育, 或可用于农村卫生、养老、文化等 其他公共服务。二是对产权有争议的闲置校产, 按照 “先 利用、后确权” 原则, 在征求群众同意的基础上, 先用起 来, 再开展产权梳理确认工作。三是对公共服务难以利用 的, 遵从民意可通过置换、变卖、出租等方式获得收益, 在偿还学校债务后按投入比例进行分配。四是对年代久远、 建筑质量差的校舍, 应尽快拆除, 消除安全隐患。

\section{3 合理配置国有资源}

由教育部门、国有资产管理部门, 实行阳光操作, 根
据实际, 按照法定程序公开处理, 最大限度地减少不和谐 因素。结合所在乡镇人民政府、所在村委会, 从实际出发 进行合理利用, 优先保证用于发展教育事业。一是兴办幼 儿教育, 提升农村学前教育办园水平; 二是兴办成人教育, 办成 “新农村大学堂”、村级文化技术培训学校、村级文化 园地等; 三是兴办勤工俭学基地, 以开展农村劳动力转移 培训、实用技术推广和社区教育为重点, 提高农民的科技 文化水平; 四是作为合并后学校的校外教育活动后备基地, 鼓励发展农村社会公益性事业。五是不宜发挥以上作用的, 以招标方式出卖或出租, 没有人竞标或承包的, 由上级教 育部门和国有资产管理部门以书面的形式委托村委会管 理。六是任何单位和个人不得随意侵占、变卖校产。

最后, 笔者认为, 只有认真解决农村人口流动与教育 资源的优化配置的问题, 合理地再利用农村 “废校” 设施, 提升国有资产和资源的附加价值, 充分体现学校教育的社 会公益功能和公共服务职能, 才能更好地获得经济、社会 效益和高素质的人力资源, 满足教育和人力资源开发需要, 促进城乡一体化、统筹协调和农村经济社会和谐发展; 才 能让人民对教育满意, 在中国特色社会主义道路上实现中 华民族伟大复兴和全面建成小康社会的宏伟目标。

\section{参考文献(References)}

[1] ITO yoshiyiti, Across the hydrophobic region of opinions, The public opinion of the central, 1967.6.

[2] Imai satihiko, A thin strip of Japan, Iwaba bookstore, 1968.

[3] Anda constant, Thin strip of agricultural management and life, The earth, 1967.6.

[4] Naitou masanaka, A hydrophobic and new production, Imai bookstore, 1968.

[5] Morioka kiyomi, The new dictionary of sociology, Yuhigaku, 1993.

[6] Simomura tetuo, Under the education laws and regulations, Gakuyou syobou, 2004.

[7] Ekita syouzou, The village social changes and pathological - shu village of solid state, Through publishing co., LTD, 1979.

[8] Liu Yansui, Liu Yu, Zhai Rong Xin, The geography research and control of China's rural hollowing out, practice, Journal of geographical, 2009.10.

[9] Cheng Liansheng, Feng Wenyong, Southeast of the taiyuan basin hollowing out mechanism analysis of rural settlements, Journal of geographical, 2001.4.

[10] He Fang, Zhou Lu, Hollowing out mechanism based on the push-pull model village, Economic research, 2010.8.

[11] Jiao bifang, Sun Binbin, The Japanese official merger and its influence on the modern rural construction, Modern Japan's economy, 2008.5.

[12] http://www.iinan.jp/category_lst.php?sid=408

[13] http://learning.sohu.com/20121118/n357916460.shtml 